\title{
SIMULASI PENGARUH UKURAN PARTIKEL DAN EQUIVALENCE RATIO DALAM PROSES GASIFIKASI TANDAN KOSONG KELAPA SAWIT
}

\author{
SIMULATION OF PARTICLE SIZE AND EQUIVALENCE RATIO EFFECT ON \\ GASIFICATION PROCESS OF PALM EMPTY FRUIT BUNCH
}

\author{
Sabar Pangihutan Simanungkalit, Dieni Mansur, dan Nino Rinaldi \\ Pusat Penelitian Kimia - LIPI \\ Kawasan PUSPIPTEK - Serpong (Banten - Indonesia) \\ Email : saba004@lipi.go.id \\ Diterima : 15 Juli 2015, Revisi : 04 Agustus 2015, Disetujui : 10 September 2015
}

\begin{abstract}
ABSTRAK
Pada studi ini telah dilakukan simulasi proses gasifikasi limbah tandan kosong kelapa sawit (TKKS) menggunakan fixed bed gasifier tipe throat downdraft dengan memvariasikan ukuran partikel bahan umpan TKKS dan equivalence ratio (ER). Laju konsumsi bahan bakar adalah $10 \mathrm{~kg} / \mathrm{jam}$ dengan udara sebagai media oksidasi dan lama waktu proses dalam 1 batch adalah 1 jam. Simulasi dilakukan dengan pendekatan dua dimensi (2D) menggunakan perangkat lunak Computational Fluid Dynamics (CFD) ANSYS FLUENT 14. Hasil simulasi menunjukkan bahwa besar equivalence ratio (ER) ideal untuk proses gasifikasi limbah TKKS berbentuk pelet ber-diameter ( $\Phi$ ) $6 \mathrm{~mm}$ dan $8 \mathrm{~mm}$ adalah $0,1 \leq \mathrm{ER} \leq 0,2$. Variasi ER mempengaruhi HHV (Higher Heating Value) syngas hasil gasifikasi, efisiensi karbon ( $\mathrm{c})$, efisiensi gasifikasi serta distribusi temperatur dalam reaktor gasifikasi. Variasi ukuran partikel tidak memberikan efek yang signifikan dalam proses gasifikasi.
\end{abstract}

Kata kunci: CFD, gasifikasi TKKS, ukuran partikel, equivalence ratio

\footnotetext{
ABSTRACT

In this study, a simulation for gasification process of oil palm empty fruit bunches waste (OPEFB) using a fixed bed gasifier (throat downdraft) by varying the particle size of OPEFB and equivalence ratio (ER) was investigated. The rate of fuel consumption was $10 \mathrm{~kg} / \mathrm{h}$ with air as the oxidizing medium and 1 hour process time for 1 batch. Simulation was performed with twodimensional approach (2D) using Computational Fluid Dynamics (CFD) ANSYS FLUENT 14 software. Simulation results show that ideal amount of equivalence ratio (ER) for gasification process of
}

OPEFB pellets with diameter $(\varphi)$ of $6 \mathrm{~mm}$ and 8 $m m$ is $0.1 \leq E R \leq 0.2$. ER variation affects the higher heating value of syngas (HHV), the carbon efficiency $\left(\eta_{C}\right)$, gasification efficiency and temperature distribution in the gasification reactor. Variations in particle size did not have a significant effect in the gasification process.

Keywords: $C F D, O P E F B$ gasification, particle size, equivalence ratio

\section{PENDAHULUAN}

Pada proses gasifikasi, bahan bakar solid (biomassa) dikonversi menjadi bahan bakar gas dalam reaktor gasifikasi (gasifier) dengan media oksidasi seperti: udara, steam, dan Oksigen $\left(\mathrm{O}_{2}\right)$. Salah satu biomassa yang dapat dikembangkan sebagai energi alternatif dengan proses gasifikasi adalah limbah tandan kosong kelapa sawit (TKKS). TKKS merupakan limbah yang dihasilkan oleh industri kelapa sawit dalam jumlah yang besar, karena dalam pemrosesan 1 ton tandan buah segar kelapa sawit akan dihasilkan limbah TKKS sekitar $23 \%$ atau $230 \mathrm{~kg}$ $\mathrm{TKKS}^{(1)}$. Indonesia merupakan salah satu Negara penghasil kelapa sawit terbesar didunia. Hingga tahun 2014, luas perkebunan kelapa sawit di Indonesia mencapai 10,85 juta hektar dengan produksi CPO (crude palm oil) 28,02 juta ton/tahun ${ }^{(2)}$. Hal ini membuat ketersediaan 
limbah TKKS di Indonesia sangat besar dan belum dimanfaatkan secara optimal.

Salah satu jenis gasifier berdasarkan kontak antara solid dan gas adalah fixed bed (unggun diam), dan gasifier jenis ini dapat diaplikasikan dalam rentang daya antara $10 \mathrm{~kW}$ hingga $10 \mathrm{MW}^{(3)}$. Sementara itu, berdasarkan arah aliran gas gasifier unggun diam dibedakan atas updraft gasifier dan downdraft gasifier ${ }^{(4,5)}$. Pada updraft gasifier, gas produk gasifikasi mengalir ke atas (berlawanan arah dengan aliran bahan umpan) sedangkan untuk downdraft gasifier gas produk gasifikasi mengalir ke bawah (searah dengan aliran bahan umpan). Gasifier jenis unggun diam merupakan jenis gasifier yang simpel dan aplikatif. Sekitar $89 \%$ proses gasifikasi batubara di dunia menggunakan gasifier unggun diam ${ }^{(6)}$. Gasifier unggun diam merupakan teknologi yang paling cocok untuk pemrosesan energi dari biomassa dan limbah padat perkotaan ${ }^{(7)}$.

Penelitian tentang downdraft gasifier sebagian besar memanfaatkan biomassa sebagai bahan umpan. Penggunaan sisa serbuk gergaji dengan menerapkan sistem sirkulasi gas menunjukkan bahwa ukuran partikel dari serbuk gergaji menjadi sebuah permasalahan tersendiri dalam proses gasifikasi. Sedangkan dengan adanya sirkulasi gas meningkatkan kinerja dari gasifikasi secara keseluruhan ${ }^{(8)}$. Sementara itu, pemanfaatan limbah industri furniture dan potongan kayu (wood chip) sebagai bahan umpan dalam downdraft gasifier menyimpulkan bahwa batas equivalence ratio (ER) untuk proses gasifikasi serbuk gergaji dan potongan kayu yang ideal adalah antara $0,19-0,43^{(9)}$. Equivalence ratio (ER) adalah hasil bagi antara perbandingan jumlah udara dan bahan bakar aktual (terukur) dengan perbandingan jumlah udara dan bahan bakar stoichiometric. Dari hasil penelitian diatas, ukuran partikel biomassa dan equivalence ratio menjadi parameter yang penting dalam gasifikasi biomassa.
Penelitian-penelitian downdraft gasifer terus dilakukan baik dengan metode eksperimen maupun simulasi. Model simulasi tersebut dapat diklasifikasikan dalam 4 kelompok, yakni: (1) Kinetik, (2) Computational Fluid Dynamics (CFD), (3) Kesetimbangan termodinamika dan (4) Artificial neural networks $^{(3)}$. CFD merupakan salah satu perangkat lunak untuk aplikasi dinamika fluida, dengan kemajuan dalam metode numerik dan teknologi perangkat keras (hardware) sangat memungkinkan digunakannya CFD untuk mensimulasikan proses gasifikasi $^{(10)}$. Namun referensi tentang simulasi proses gasifikasi dalam gasifier unggun diam menggunakan CFD jumlahnya masih sangat sedikit ${ }^{(11)}$. Oleh karena itu dalam studi ini telah dilakukan simulasi proses gasifikasi limbah TKKS dalam gasifier unggun diam (throat downdraft) menggunakan perangkat lunak CFD ANSYS FLUENT 14. Simulasi bertujuan untuk melihat pengaruh ukuran partikel dan equivalence ratio terhadap komposisi gas dan performa dari proses gasifikasi limbah TKKS.

\section{METODOLOGI}

\section{Karakterisasi bahan umpan}

Bahan umpan yang digunakan dalam studi ini adalah limbah TKKS berbentuk pelet berdiameter $(\phi) 6 \mathrm{~mm}$ dan $8 \mathrm{~mm}$, dimana hasil analisa ultimate dan proximate bahan umpan tersebut dinyatakan dalam Tabel $1^{(12,13)}$. Data-data tersebut dimasukkan sebagai properti material dalam simulasi CFD.

\section{Konfigurasi geometri gasifier}

Salah satu proses dalam tahap awal (pre-processor) simulasi CFD adalah mendefenisikan geometri model, dalam hal ini geometri throat downdraft gasifier. Geometri downdraft gasifier yang 
digunakan dalam studi ini berdiameter (D) $30 \mathrm{~cm}$ dan tinggi $(\mathrm{H}) 135 \mathrm{~cm}^{(14)}$. Letak tenggorokan (throat) dari gasifikasi adalah $45 \mathrm{~cm}$ dari dasar gasifier dengan diameter pipa inlet udara sebagai media oksidasi dan outlet syngas adalah $5 \mathrm{~cm}$ (Gb.1.a). Proses meshing terhadap geometri throat downdraft gasifier menggunakan perangkat lunak GAMBIT 2.3.16. Mesh dari throat downdraft gasifier dalam 2 dimensi (2D) ditunjukkan pada Gb.1.b, terdiri dari 2236 cell berbentuk elemen triangle tipe pave.

Tabel 1. Analisa proximate dan ultimate TKKS berbentuk pelet

\begin{tabular}{|c|c|c|}
\hline & $\Phi 6 \mathrm{~mm}$ & $\Phi 8 \mathrm{~mm}$ \\
\hline \multicolumn{3}{|l|}{ Proximate analysis (wt.\%) } \\
\hline Moisture & 11 & 11.3 \\
\hline Ash & 7.9 & 7.9 \\
\hline Fixed Carbon & 8.36 & 8.36 \\
\hline Volatiles (diff.) & 72.74 & 72.44 \\
\hline \multicolumn{3}{|l|}{ Ultimate analysis (wt.\%) } \\
\hline Carbon & 47.2 & 47.2 \\
\hline Hydrogen & 6 & 6 \\
\hline Nitrogen & 0.6 & 0.6 \\
\hline Oxygen (diff.) & 38.2 & 38.2 \\
\hline Sulfur & 0.12 & 0.12 \\
\hline LHV, MJ/kg (dry basis) & 18.05 & 18.05 \\
\hline LHV, MJ/kg (dry basis) & 19.35 & 19.35 \\
\hline Bulk density $\left(\mathrm{kg} / \mathrm{m}^{3}\right)$ & 630 & 580 \\
\hline Diameter $(\mathrm{mm})$ & 6 & 8 \\
\hline Stoichiometric AFR $(\mathrm{kg} / \mathrm{kg})^{*}$ & 5.87 & 5.87 \\
\hline
\end{tabular}

Sebagaimana yang telah diketahui, untuk mencegah terjadinya pembakaran sempurna dalam proses gasifikasi maka jumlah media oksidasi (udara) harus dapat dikendalikan. Perbandingan jumlah bahan bakar dengan udara sebagai media oksidasi dalam proses gasifikasi biasanya dinyatakan dengan parameter Equivalence Ratio (ER). Variasi ER dalam studi ini adalah $0.10,0.15,0.20$ dan 0.25 dengan masing-masing laju massa udara $\left(\mathrm{W}_{\mathrm{b}}\right)=$ $1.6 \mathrm{e}^{-3}, 2.4 \mathrm{e}^{-3}, 3.2 \mathrm{e}^{-3}$ dan $4.0 \mathrm{e}^{-3} \mathrm{~kg}$ per detik. (a)

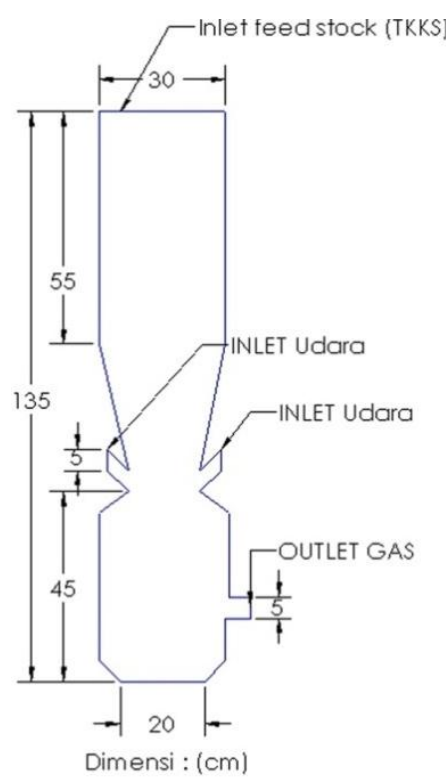

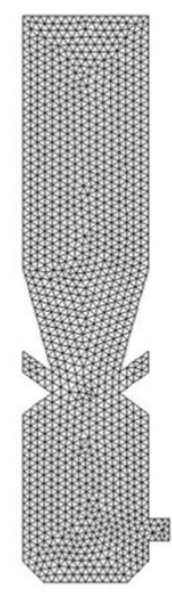

(b)
Gambar 1. Throat downdraft gasifier, (a) Geometri, (b) Mesh

\section{Model komputasi}

Simulasi CFD dalam studi ini merupakan pendekatan 2 dimensi (2D), dimana untuk proses solver dan postprocessor digunakan perangkat lunak CFD ANSYS FLUENT 14 dengan model komputasi seperti ditampilkan dalam Tabel 2. Untuk memodelkan interaksi antara reaksi proses gasifikasi dengan turbulensi digunakan finite rateleddy dissipation. Sementara itu, untuk model pergerakan partikel TKKS (particle trajectory) dalam gasifier maka dipakai model fase diskrit yang dikopel dengan fase kontinyu. Simulasi dilakukan hingga 3000 iterasi, dimana pada saat tersebut residual dari perhitungan tidak berubah lagi (konstan). 


\section{Model reaksi gasifikasi}

Model reaksi proses gasifikasi yang digunakan dalam simulasi adalah:

a. Reaksi dekomposisi volatile ${ }^{(15)}$

Volatil $+0.437 \mathrm{O}_{2} \quad \rightarrow \quad 0.95 \mathrm{CO}+0.95 \mathrm{H}_{2} \mathrm{O}+0.014 \mathrm{~N}_{2}$

b. Reaksi Karbon ${ }^{(3)}$

$\begin{array}{llll}\mathrm{C} & +0.5 \mathrm{O}_{2} & \rightarrow & \mathrm{CO} \\ \mathrm{C} & +\mathrm{CO}_{2} & \rightarrow & 2 \mathrm{CO} \\ \mathrm{C} & +\mathrm{H}_{2} \mathrm{O} & \rightarrow & \mathrm{CO}+\mathrm{H}_{2} \\ \mathrm{C} & +2 \mathrm{H}_{2} & \rightarrow & \mathrm{CH}_{4} \\ \mathrm{C} & +\mathrm{O}_{2} & \rightarrow & \mathrm{CO}_{2}\end{array}$

c. Reaksi fase gas ${ }^{(3)}$

$\mathrm{CO}+\mathrm{H}_{2} \mathrm{O} \quad \leftrightarrow \quad \mathrm{CO}_{2}+\mathrm{H}_{2}$

Dimana $\mathrm{Q}_{\mathrm{a}}$ adalah laju alir volume dari udara sebagai media oksidasi $\left(\mathrm{Nm}^{3} / \mathrm{jam}\right)$ dan dinyatakan dalam persamaan 5 . $\mathrm{W}_{\mathrm{b}}$ adalah laju alir massa dari bahan umpan $(\mathrm{kg} / \mathrm{jam})$ dalam hal ini adalah TKKS, dan $\mathrm{N}_{2} \%$ adalah persentase volume dari gas Nitrogen dalam syngas hasil gasifikasi. Sementara itu, $\mathrm{H}_{\mathrm{g}}$ $\left(\mathrm{MJ} / \mathrm{Nm}^{3}\right)$ dan $\mathrm{H}_{\mathrm{b}}(\mathrm{MJ} / \mathrm{kg})$ adalah higher heating value dari syngas hasil gasifikasi dan biomassa (TKKS).

Dengan SA adalah stoichiometric air fuel ratio, FCR adalah fuel consumption rate $(\mathrm{kg} / \mathrm{jam})$ dan $\rho_{\mathrm{a}}$ adalah massa jenis udara $=1.2 \mathrm{~kg} / \mathrm{m}^{3}$. Berdasarkan perhitungan, maka besarnya laju alir volume udara yang digunakan untuk variasi ER $0.10,0.15,0.20$ dan 0.25 adalah $4.89,7.34,9.78$ dan $12.22 \mathrm{Nm}^{3} / \mathrm{jam}$.

\section{HASIL DAN PEMBAHASAN}

\section{Distribusi Temperatur}

Distribusi temperatur merupakan salah satu parameter yang penting dalam proses gasifikasi, karena besarnya temperatur menunjukkan reaktifitas biomassa sebagai bahan bakar dalam proses gasifikasi. Semakin reaktif bahan bakar akan meningkatkan besaran temperatur dan produksi gas dalam proses gasifikasi, sedangkan bahan bakar yang kurang reaktif akan menghasilkan lebih banyak Nitrogen cair dan suhu yang rendah pada reaktor gasifikasi ${ }^{12}$. Gambar. 2 menunjukkan grafik distribusi temperatur rata-rata hasil simulasi disepanjang tinggi reaktor gasifikasi. Dalam grafik tersebut terlihat bahwa untuk setiap variasi ER dan ukuran partikel TKKS, temperatur maksimum $\left( \pm 1200{ }^{\circ} \mathrm{C}\right)$ berada pada lokasi throat disekitar ujung pipa inlet udara. Hal ini dihubungkan dengan konsentrasi Oksigen paling banyak berada pada lokasi tersebut, sehingga reaksi oksidasi carbon mendominasi. Hasil simulasi pengaruh variasi ER dan ukuran partikel TKKS terhadap distribusi temperatur dalam gasifier memiliki tren yang sama dengan hasil eksperimen yang memanfaatkan kulit kayu pinus sebagai bahan umpan ${ }^{(17)}$. Penulis melaporkan semakin tinggi nilai ER maka jumlah udara yang masuk kedalam gasifier semakin banyak, sehingga temperatur pada zona oksidasi akan semakin tinggi. Sedangkan variasi ukuran partikel tidak memberikan pengaruh yang besar terhadap temperatur maksimum dalam gasifier. 
Tabel 2. Model komputasi

\begin{tabular}{|c|c|c|c|}
\hline \multirow{8}{*}{ Models Setting } & Model & Settings & Information \\
\hline & Space & $2 D$ & Pressure based \\
\hline & Time & Steady & - \\
\hline & Viscous & $\begin{array}{l}\text { Realizable k-epsilon } \\
\text { turbulence model }\end{array}$ & $\begin{array}{c}\text { Turbulence intensity }= \\
10 \%\end{array}$ \\
\hline & Wall Treatment & Standard Wall Functions & - \\
\hline & Heat Transfer & Enabled & - \\
\hline & Species Transport & Reacting (9 species) & $\begin{array}{l}\text { Volumetric and Particle } \\
\text { surface }\end{array}$ \\
\hline & Discrete phase & Surface injection & Combustion \\
\hline \multirow{9}{*}{$\begin{array}{l}\text { Boundary } \\
\text { Condition }\end{array}$} & Name & Type & Information \\
\hline & Fluid & Fluid & $\operatorname{Air}\left(20 \% \mathrm{O}_{2}\right)$ \\
\hline & Outlet-syngas & Pressure outlet & - \\
\hline & Inlet-air & Mass-flow-inlet & $\begin{array}{l}1.6 e^{-3} \mathrm{~kg} / \mathrm{s}(E R=0.10) \\
2.4 e^{-3} \mathrm{~kg} / \mathrm{s}(E R=0.15) \\
3.2 e^{-3} \mathrm{~kg} / \mathrm{s}(E R=0.20) \\
4.0 e^{-3} \mathrm{~kg} / \mathrm{s}(E R=0.25)\end{array}$ \\
\hline & Inlet-tkks & Mass-flow-inlet & $\begin{array}{c}2.78 e^{-3} \mathrm{~kg} / \mathrm{s} \\
\Phi=6 \mathrm{~mm} \text { and } 8 \mathrm{~mm}\end{array}$ \\
\hline & Drying & Wall (mixed) & Convection and Radiation \\
\hline & Pyrolysis & Wall (mixed) & Convection and Radiation \\
\hline & Oxidation & Wall (mixed) & Convection and Radiation \\
\hline & Reduction & Wall (mixed) & Convection and Radiation \\
\hline \multirow{6}{*}{ Solvers } & Variable & Discretization Scheme & Information \\
\hline & Pressure & PRESTO! & - \\
\hline & Momentum & Second Order Upwind & - \\
\hline & Turbulent Kinetic Energy & Second Order Upwind & - \\
\hline & Turbulent Dissipation Rate & Second Order Upwind & - \\
\hline & Energy & Second Order Upwind & - \\
\hline
\end{tabular}

$$
\begin{aligned}
& \mathrm{HHV}=\left(\mathrm{H}_{2} \% * 0.03052+\mathrm{CO} \% * 0.03018+\mathrm{CH}_{4} \% * 0.095\right) * 4.2\left(\mathrm{MJ} / \mathrm{Nm}^{3}\right) \\
& \mathrm{Y}=\frac{\mathrm{Q}_{\mathrm{a}} * 0.79}{\mathrm{~W}_{\mathrm{b}} * \mathrm{~N}_{2} \%}\left(\frac{\mathrm{Nm}^{3}}{\mathrm{~kg}}\right) \\
& \eta_{\mathrm{C}}=\frac{\mathrm{Y}\left(\mathrm{CO} \%+\mathrm{CO}_{2} \%+\mathrm{CH}_{4} \%\right) * 12}{22.4 * \mathrm{C} \%} \cdot 100 \% \\
& \eta_{\mathrm{C}}=\frac{\mathrm{H}_{\mathrm{E}} * \mathrm{Y}}{\mathrm{H}_{\mathrm{b}}} \cdot 100 \% \\
& \mathrm{Q}_{\mathrm{a}}=\frac{\mathrm{ER} * \mathrm{FCR} * \mathrm{SA}}{\rho_{\mathrm{a}}}\left(\mathrm{Nm}^{3} / \mathrm{jam}\right)
\end{aligned}
$$




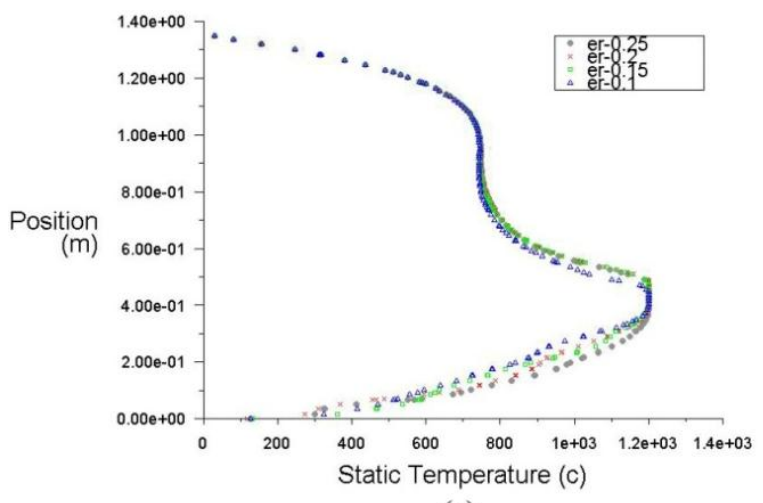

(a)

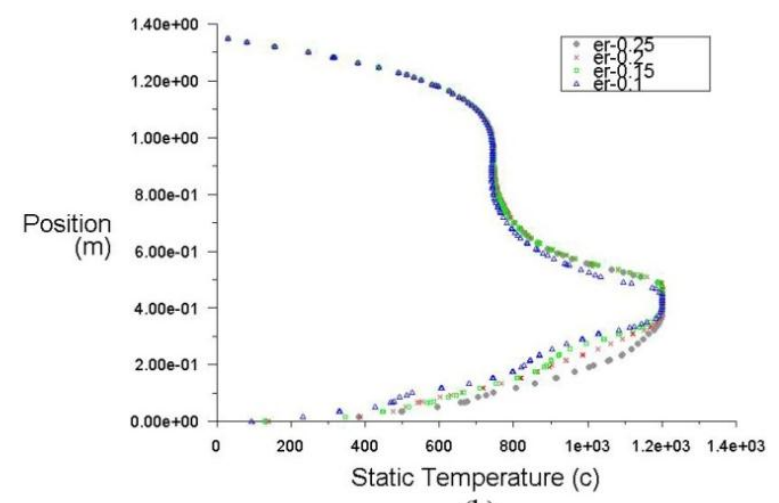

(b)

Gambar 2. Distribusi temperatur disepanjang tinggi gasifier, (a) 6mm, (b) $8 \mathrm{~mm}$

\section{Komposisi gas}

Komposisi syngas $(\%)$ hasil simulasi gasifikasi TKKS yang keluar melalui outlet untuk setiap ukuran partikel dengan variasi ER ditunjukkan pada Gb.3. Dari hasil simulasi, didapatkan tren yang sama dengan hasil penelitian gasifikasi TKKS yang telah dilakukan sebelumnya ${ }^{(12,13)}$, yakni semakin besar nilai ER maka konsentrasi gas $\mathrm{CO}, \mathrm{H}_{2}$ dan $\mathrm{CH}_{4}$ dalam komposisi syngas akan menurun, sedangkan konsentrasi gas $\mathrm{CO}_{2}$ semakin meningkat. Pada variasi $\mathrm{ER}=0.1,0.15$ dan 0.2 konsentrasi gas $\mathrm{CO}$ merupakan konsentrasi paling banyak dalam komposisi syngas, diikuti gas $\mathrm{CO}_{2}, \mathrm{H}_{2}$ dan $\mathrm{CH}_{4}$. Hal ini berarti pada rentang variasi ER tersebut masih terjadi pembakaran tidak sempurna. Sementara itu, pada ER = 0.25 konsentrasi $\mathrm{CO}_{2}$ sudah melebihi konsentrasi $\mathrm{CO}$ dalam komposisi syngas. Hal ini menandakan bahwa proses termokimia mendekati proses pembakaran sempurna (combustion). Komposisi gas $\mathrm{H}_{2}$ dalam syngas cukup rendah, yakni $\pm 3 \%$, hal ini terjadi karena rendahnya kadar moisture dari TKKS yang digunakan sebagai bahan umpan dalam studi ini, yakni $11-11.3 \%$. Hasil yang sama juga didapatkan dalam penelitian gasifikasi serbuk kayu pinus, dengan peningkatan kadar moisture serbuk kayu pinus dari 10 $\%$ menjadi $25 \%$ meningkatkan komposisi gas $\mathrm{H}_{2}$ dalam syngas dari $5 \%$ menjadi 9 $\%^{(18)}$.

\section{Nilai kalor gas}

Tabel 3 menyatakan besarnya nilai kalor (HHV) dan dry gas yield (Y) hasil simulasi gasifikasi TKKS untuk setiap ukuran partikel TKKS dengan variasi ER. Besarnya HHV dan Y dihitung berdasarkan pers. (1) dan (2).

Untuk kedua ukuran partikel TKKS, HHV maksimum terdapat pada ER $=0.1$. Pada kondisi ini konsentrasi combustible gas $\left(\mathrm{CO}, \mathrm{H}_{2}\right.$ dan $\left.\mathrm{CH}_{4}\right)$ berada pada jumlah maksimum. Semakin besar nilai ER maka konsentrasi combustible gas akan menurun sehingga mengakibatkan menurunnya nilai kalor (HHV) dari syngas. Hasil yang sama juga didapatkan dalam hasil eksperimen gasifikasi TKKS yang telah dilaporkan sebelumnya $^{(9,13)}$. Sedangkan perbedaan ukuran partikel TKKS tidak menimbulkan pengaruh yang signifikan terhadap nilai kalor (HHV) syngas, dimana selisih HHV syngas hasil gasifikasi TKKS ber-diameter $8 \mathrm{~mm}$ dengan $6 \mathrm{~mm}$ hanya berkisar $0.01-$ $0.02 \mathrm{MJ} / \mathrm{Nm}^{3}$. Sementara itu, semakin besar nilai ER maka dry gas yield (Y) akan meningkat juga sebagai akibat dari bertambahnya jumlah volume udara yang masuk kedalam gasifier. 


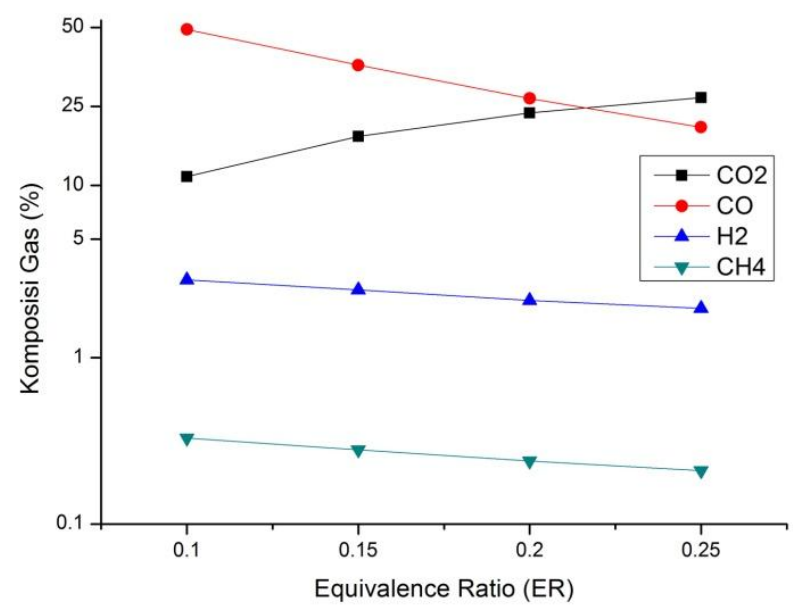

(a)

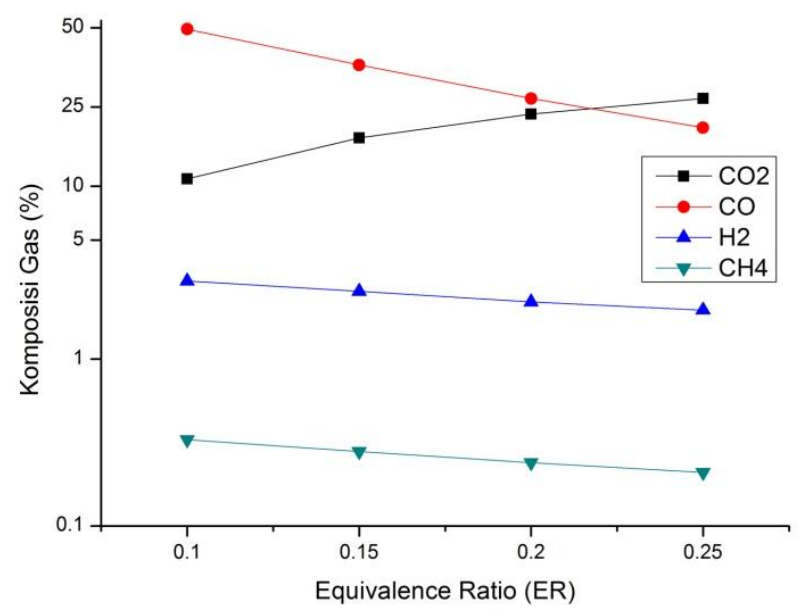

(b)

Gambar 3. Komposisi syngas hasil gasifikasi, (a) $6 \mathrm{~mm}$, (b) $8 \mathrm{~mm}$

Tabel 3. Nilai kalor (HHV) dan dry gas yield (Y) syngas

\begin{tabular}{|c|c|c|c|c|}
\hline \multirow{2}{*}{ ER } & \multicolumn{2}{|c|}{$6 \mathrm{~mm}$} & \multicolumn{2}{|c|}{$8 \mathrm{~mm}$} \\
\hline & $\begin{array}{c}\text { HHV } \\
\left(\mathrm{MJ} / \mathrm{Nm}^{3}\right)\end{array}$ & $\begin{array}{c}\mathbf{Y} \\
\left(\mathrm{Nm}^{3} / \mathrm{kg}\right)\end{array}$ & $\begin{array}{c}\text { HHV } \\
\left(\mathrm{MJ} / \mathrm{Nm}^{3}\right)\end{array}$ & $\begin{array}{c}\mathbf{Y} \\
\left(\mathrm{Nm}^{3} / \mathrm{kg}\right)\end{array}$ \\
\hline 0.1 & 6.73 & 1.07 & 6.75 & 1.07 \\
\hline 0.15 & 5.14 & 1.39 & 5.16 & 1.39 \\
\hline 0.2 & 3.81 & 1.65 & 3.82 & 1.65 \\
\hline 0.25 & 2.86 & 1.92 & 2.87 & 1.92 \\
\hline
\end{tabular}

\section{Kinerja gasifikasi}

Tabel 4 menyatakan besarnya efisiensi karbon $\left(\eta_{\mathrm{C}}\right)$ dan efisiensi gasifikasi ( $\eta$ ) hasil simulasi gasifikasi TKKS untuk setiap ukuran partikel TKKS dengan variasi $E R$, dimana besarnya $\eta_{C}$ dan $\eta(\%)$ dihitung berdasarkan pers. (3) dan (4).

Untuk kedua ukuran partikel TKKS, semakin besar ER maka efisiensi karbon $\left(\eta_{C}\right)$ akan semakin meningkat juga. Sementara itu, besarnya efisiensi gasifikasi ( $\eta$ ) sangat bergantung pada HHV syngas hasil gasifikasi ${ }^{(13)}$, sehingga semakin besar nilai ER maka $\eta(\%)$ akan menurun seiring dengan menurunnya nilai kalor (HHV) dari syngas.
Tabel 4. Efisiensi karbon $\left(\eta_{C}\right)$ dan efisiensi gasifikasi ( $\eta)$

\begin{tabular}{|c|c|c|c|c|}
\hline \multirow{2}{*}{ ER } & \multicolumn{2}{|c|}{$6 \mathrm{~mm}$} & \multicolumn{2}{|c|}{$8 \mathrm{~mm}$} \\
\hline & $\eta_{C}(\%)$ & $\eta(\%)$ & $\eta_{C}(\%)$ & $\eta(\%)$ \\
\hline 0.1 & 73.90 & 37.26 & 73.84 & 37.36 \\
\hline 0.15 & 87.72 & 36.96 & 87.67 & 37.09 \\
\hline 0.2 & 94.94 & 32.43 & 94.87 & 32.52 \\
\hline 0.25 & 100.00 & 28.45 & 100.00 & 28.46 \\
\hline
\end{tabular}

\section{KESIMPULAN}

Berdasarkan hasil simulasi, besar equivalence ratio (ER) ideal untuk proses gasifikasi limbah TKKS berbentuk pelet ber-diameter $(\phi) 6 \mathrm{~mm}$ dan $8 \mathrm{~mm}$ adalah $0,1 \leq \mathrm{ER} \leq 0,2$. Variasi ER mempengaruhi HHV (Higher Heating Value) syngas hasil gasifikasi, efisiensi karbon $\left(\eta_{C}\right)$, efisiensi gasifikasi serta distribusi temperatur dalam reaktor gasifikasi. Sedangkan variasi ukuran partikel tidak memberikan efek yang signifikan dalam proses gasifikasi.

\section{UCAPAN TERIMA KASIH}

Penulis mengucapkan terima kasih kepada Pusat Penelitian Kimia - LIPI yang 
telah menyediakan sarana dan prasarana dalam penelitian serta memberikan ijin untuk mempublikasikan tulisan ilmiah ini.

\section{DAFTAR PUSTAKA}

1. M.S. Umikalsom, A.B. Ariff, H.S. Zulkifli, C.C. Tong, M.A. Hassan, M.I.A. Karim. The treatment of oil palm empty fruit bunch fiber for subsequent use as substrate for cellulose production by Chaetomium globosum Kunze. J. Bioresource Technology 62: 1-9 (1997).

2. Sub Direktorat Statistik Tanaman Perkebunan. Statistik Kelapa Sawit Indonesia 2013. Badan Pusat Statistik, Jakarta, 2013.

3. P. Basu. Biomass Gasification and Pyrolysis: Practical Design and Theory. Elsevier Inc., Oxford, 2010.

4. A. Rajvanshi. Alternative Energy in Agriculture: Biomass Gasification, Vol. II, Ed. CRC Press, Maharashtra, 1986, pp 83-102.

5. T. Reed, A. Das. Handbook of Biomass Downdraft Gasifier Engine Systems. Biomass Energy Foundation, 1988.

6. M.L. Hobbs, P.T. Radulovic, L.D. Smoot. Combustion and gasification of coals in fixed-beds. Progress in Energy and Combustion Science 19: 505-586 (1993).

7. Y. Yang, V. Sharifi, J. Swithenbank. Effect of air flow rate and fuel moisture on the burning behaviours of biomass and simulated municipal solid wastes in packed beds. Fuel 83: 1553-1562 (2004).

8. P.R. Wander, C.R. Altafini, R.M. Barreto. Assessment of a small sawdust gasification unit. Biomass Bioenergy 27(5): 467-476 (2004).
9. Z.A. Zainal, A. Rifau, G.A. Quadir, K.N. Seetharamu. Experimental investigation of a downdraft biomass gasifier. Biomass Bioenergy 23(4): 283-289 (2002).

10. S. Murgia, M. Vascellari, G. Cau. Comprehensive CFD model of an airblown coal-fired updraft gasifier. Fuel 101: 129-138 (2012).

11. A. Rogel, J. Aguillon. The 2D Eulerian Approach of Entrained Flow and Temperature in a Biomass Stratified Downdraft Gasifier. American Journal of Applied Sciences 3(10): 2068-2075 (2006).

12. C. Erlich, T.H. Fransson. Downdraft gasification of pellets made of wood, palm-oil residues respective bagasse: Experimental study. Applied Energy 88: 899-908 (2011).

13. P. Lahijani, Z.A. Zainal. Gasification of palm empty fruit bunch in a bubbling fluidized bed: A performance and agglomeration study. Bioresource Technology 102: 2068-2076 (2011).

14. S.P. Simanungkalit. Simulasi numerik proses gasifikasi limbah tandan kosong kelapa sawit. J. Ketenagalistrikan dan Energi Terbarukan 12(1): 11 - 20 (2013).

15. ANSYS Inc. ANSYS FLUENT User's Guide. Technology Drive, Canonsburg, 2011.

16. R. Xiao, M. Zhang, B. Jin, Y. Huang. High-temperature air/steam-blown gasification of coal in a pressurized spout-fluid bed. Energy \& Fuels 20: 715-720 (2006).

17. F.V. Tinaut, A. Melgar, J.F. Perez, A. Horrillo. Effect of biomass particle size an air superficial velocity on gasification process in a downdraft fixed bed gasifier: An experimental and modeling study. Fuel Processing Technology 89: 1076-1089 (2008). 
18. I. Narvaez, A. Orio, M. Aznar, J. Corella. Biomass gasification with air in an atmospheric bubbling fluidized bed: Effect of six operational variables on the quality of the produced raw gas. Ind. Eng. Chem. Res. 35(7): 2110-2120 (1996). 
JKTI, Vol. 17, No. 2, Desember 2015 